\title{
Strain Distribution Measurement of a Shear Panel Damper Developed for Bridge Structure
}

\author{
Y. Liu, ${ }^{1}$ T. Aoki, ${ }^{2}$ and M. Shimoda ${ }^{1}$ \\ ${ }^{1}$ Department of Advanced Science and Technology, Toyota Technological Institute, 2-12-1 Hisakata, Tenpaku-ku, Nagoya, \\ Aichi Prefecture 468-8511, Japan \\ ${ }^{2}$ Depatrment of Urban and Environment, Aichi Institute of Technology, 1247 Yachigusa, Yakusa Cho, Toyota City, \\ Aichi Prefecture 470-0392, Japan \\ Correspondence should be addressed to Y. Liu; liuyang@toyota-ti.ac.jp
}

Received 4 June 2013; Accepted 10 August 2013

Academic Editor: Lucio Nobile

Copyright (C) 2013 Y. Liu et al. This is an open access article distributed under the Creative Commons Attribution License, which permits unrestricted use, distribution, and reproduction in any medium, provided the original work is properly cited.

A shear panel damper using low-yield steel is considered as one of cost-effective solutions to reduce earthquake damage to building structure. In this paper, we describe the development of a shear panel damper with high deformation capacity, which is a necessary condition for it to be a bridge bearing. The development is based on the measurement of strain distribution of the shear panels under cyclic loading test. For the measurement, an image processing technique is proposed to use with the two-dimensional finite element method, in which a constant stress triangular element is employed. The accuracy of the measurement is validated by comparing with the results acquired by strain gauges. Various shapes of shear panels are tested in the experiment to obtain the relationship between the strain distribution and the deformation capacity. Based on the results of the experiment, the shear panel damper is improved to achieve high seismic performance with large deformation capacity.

\section{Introduction}

Shear panel dampers (SPDs) made of low-yield steel have been widely studied and applied to high-rise buildings as hysteretic dampers globally. When shear panel dampers are installed into building structures, they are expected to partially divert the input seismic energy into the dampers and reduce the seismic response of the structures under strong earthquake loads effectively and economically and to improve the energy dissipation capacity of the buildings [13]. The researches regarding bridge structures are presently insufficient [4]. Recently, an application of SPD bearing is proposed for function separated bridge bearings system [5, 6], in which two separate bearings are designed according to each separated functional requirement. The SPD serves as a hysteretic damper and a lateral resistant bearing for seismic loads. A sliding bearing supports the vertical force including dead and live loads. This separate bearings system is expected to overcome the disadvantage of high cost and low energy dissipation capacity of laminated rubber bearing, which is installed in bridge structures generally. However, the bearings will undergo a large range of shear deformation when large relative displacement between the substructure and the bridge pier occurs in a strong earthquake. Therefore, to be a type of hysteretic damper for bridge bearing, it is strongly required to sustain high deformation capacity and repetition durability for low cycle fatigue under cyclic seismic loading.

In recent years, we have focused on developing high seismic performance shear panel damper made of the super low-yield steel LY100 with the aim of applying them in bridge structures $[7,8]$. In previous studies, we used relatively thickwalled panels to avoid out-of-plane buckling and conducted loading tests with the panels of differently shaped corners or with/without vertical stiffeners at both sides. In the cyclic loading tests, cracks were found at the four corners or two edges (left and right) of the shear panels because of the stress concentration and progressed with increasing plastic strain, which decreases the steady energy absorption capacity and finally resulted in destruction. In order to clarify the crack 
initiation mechanism in shear panel dampers made of lowyield steel, it is important to know the strain distribution in the panel. While strain gauges are commonly used to measure the strain in shear panels, it is difficult to measure up to the large strain range by strain gauges. Moreover, because a strain gauge introduces a strain at the point where it is attached, it is not easy to obtain the strain distribution in the whole panel. On the other hand, it is also difficult for the approach of numerical analysis to obtain the true strain value because of complex strain hardening of the super low-yield steel LY100 under cyclic loading.

The use of digital cameras and image processing in strain measurement has been extensively investigated due to the development of high-performance technology and price reduction of digital cameras during the past 30 years. These studies include strain measurements in materials forming processes $[9,10]$, the investigation of mechanical properties of thin film in MEMS [11], creep of metals at high temperatures [12], and analysis of the fracture behavior of structures [13, 14]. However, the strain measurements in most of these studies are confined to a limited measurement domain, and there are few investigations on strain distribution measurements in a wide target area.

In this paper, with the aim of obtaining the strain distribution in the panel of SPD, we present a large strain distribution measurement system by using image processing technique combined with the two-dimensional finite element method with a constant stress triangular element. The strains measured with the proposed method is validated by strain gauges, especially, in the large strain range. The relationship between the shear load-displacement and the strain distribution in the panels is studied to identify the crack initiation mechanism in the shear panel dampers, which can lead to the development of a high seismic performance shear panel damper with large deformation capacity.

\section{Strain Distribution Measurement by Image Processing}

The basic knowledge and general methods of image processing techniques are available in books or papers, for example, $[15,16]$, and the details of that are abbreviated in this paper.

2.1. Flowchart of Image Measurements. The flowchart for obtaining the image data from a digital camera and the calculation of the stress are shown in Figure 1. Circular red marks are painted on the white background of the lower half side of each panel specimen in advance, as shown in Figure 2. The diameter of each mark is about $0.2 \sim 0.3 \mathrm{~mm}$ and the distance between them is about $5 \mathrm{~mm}$.

After these marks are recorded by a high-precision digital camera, the points are specified on the imaginary coordinates by using image processing. Subsequently, the strain is calculated using the two-dimensional finite element method (2D-FEM) with a constant stress triangular element, where the nodal points coincide with the marks on the imaginary coordinates. The image processing part in Figure 1 is as follows.

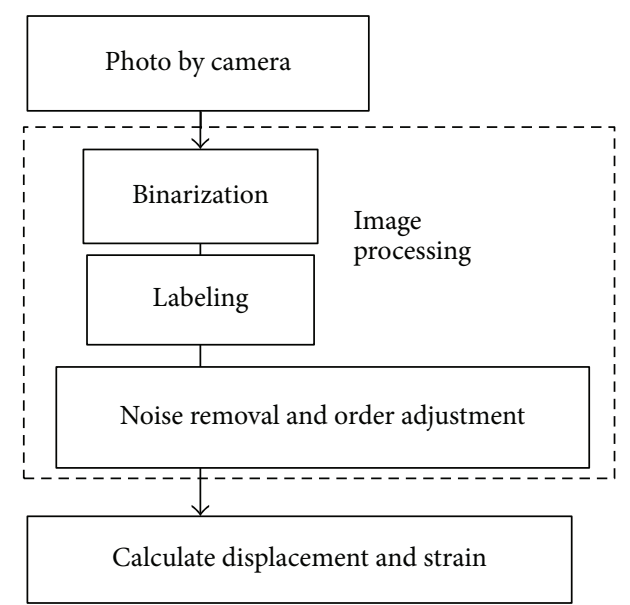

FIGURE 1: Flowchart of image measurements.

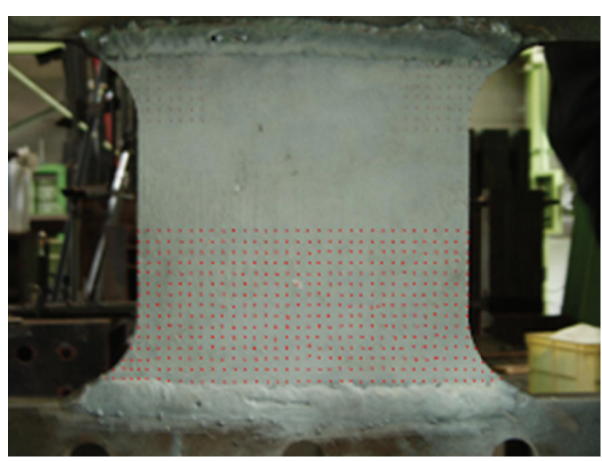

Figure 2: Position of the marks.

(1) Binarization. After selecting a suitable threshold value based on the color information of the image, each mark and background is binarized to 0 or 1 , so that the marks can be extracted from the background (Figures $3(\mathrm{a})$ and $3(\mathrm{~b}))$.

(2) Labeling. Labeling is performed by numbering each mark and calculating the coordinates of the gravity point of the area given as an assembly of pixels for each mark (Figure 3(c)).

(3) Noise removal and order adjustment. When the area of a point is considerably smaller than the rest, this point is treated as a noise particle and removed from the image. If a specimen experiences large transformation during loading, the regularly arranged mark numbers are easy to distinguish.

2.2. Calculation of Strain. We used the two-dimensional finite element method (2D-FEM) with a constant stress triangular element [17] in the strain calculations. Three points whose coordinates were obtained by image processing were designated as $i, j$, and $k$, as shown in Figure 4. The displacement increment of each node between two loading steps is written as

$$
\{d \delta\}=\left\{\begin{array}{llllll}
d u_{i} & d v_{i} & d u_{j} & d v_{j} & d u_{k} & d v_{k}
\end{array}\right\}^{T} .
$$




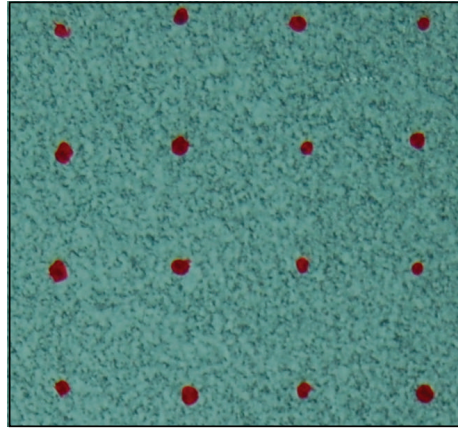

(a) Original image

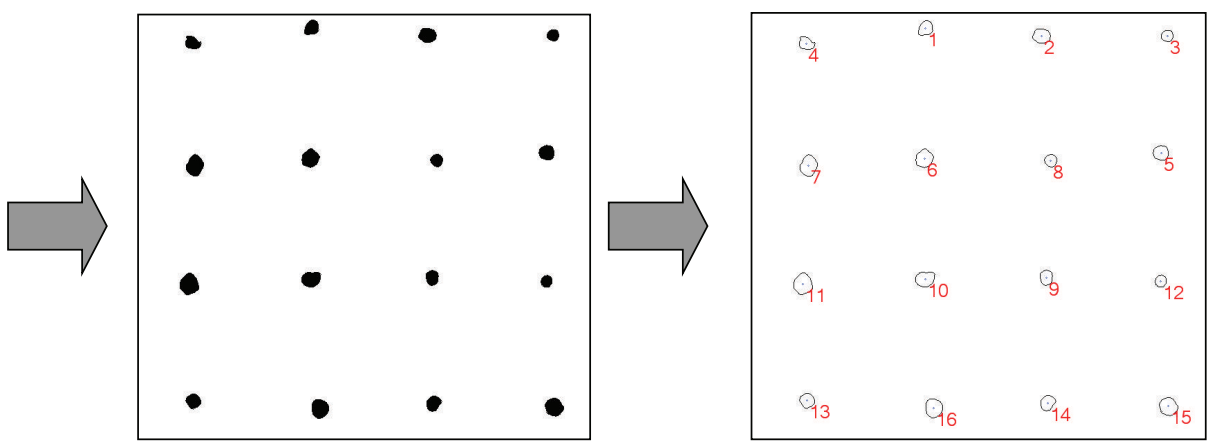

(b) Binarization

(c) Labeling

FIGURE 3: Flowchart of image processing.

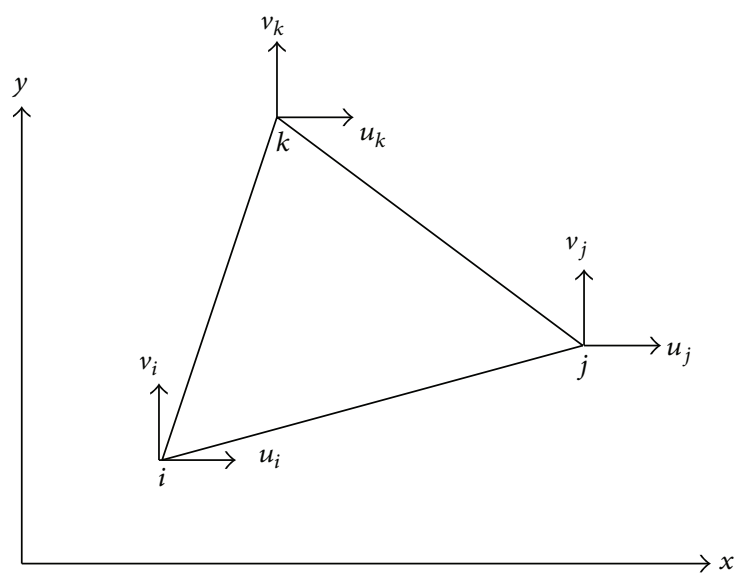

FIgURE 4: Triangular element.

The three strain components are calculated using (1) and (2) as follows:

$$
\begin{aligned}
& \{d \varepsilon\}=\left\{\begin{array}{lll}
d \varepsilon_{x} & d \varepsilon_{y} & d \gamma_{x y}
\end{array}\right\}^{T}=\left\{\begin{array}{lll}
\frac{\partial d u}{\partial x} & \frac{\partial d v}{\partial y} & \frac{\partial d u}{\partial x}+\frac{\partial d v}{\partial y}
\end{array}\right\}^{T} \\
& =\frac{1}{2 A}\left[\begin{array}{cccccc}
y_{j}-y_{k} & 0 & y_{k}-y_{i} & 0 & y_{i}-y_{j} & 0 \\
0 & x_{k}-x_{j} & 0 & x_{i}-x_{k} & 0 & x_{j}-x_{i} \\
x_{k}-x_{j} & y_{j}-y_{k} & x_{i}-x_{k} & y_{k}-y_{i} & x_{j}-x_{i} & y_{i}-y_{j}
\end{array}\right] d \delta,
\end{aligned}
$$

where $A$ is the area of the triangular element, and $x_{i}$ and $y_{i}$ are the coordinates of nodal point.

Regardless of (2) being based on the infinitesimal deformation theory, and the large deformation of SPD in the cyclic loading test; strain calculation by (2) is applicable with the assumption of linearity in the small displacement increment measured by image processing between two loading steps.

\subsection{Comparison with Results Measured by Three-Axis Gauges.} Figure 5 shows the position of the gauges on the plates. The comparison of the shear strain measured by the image analysis system and three-axis gauges is shown in Figure 6.
The shear strain measured by the three-axis strain gauges is calculated using (3),

$$
\gamma=\sqrt{2\left\{\left(\varepsilon_{1}-\varepsilon_{2}\right)^{2}+\left(\varepsilon_{2}-\varepsilon_{3}\right)^{2}\right\}},
$$

where $\varepsilon_{1}, \varepsilon_{2}$, and $\varepsilon_{3}$ are the strains in the horizontal, vertical, and slant direction axis, respectively. Because the adhesive of the strain gauges becomes useless in the large displacement region of the specimen under cyclic loading, the shear strain can only be measured up to 0.05 . Within this range of strain $(0 \sim 0.05)$, it is shown that the strain measured using the image analysis system is almost equal to that measured using 


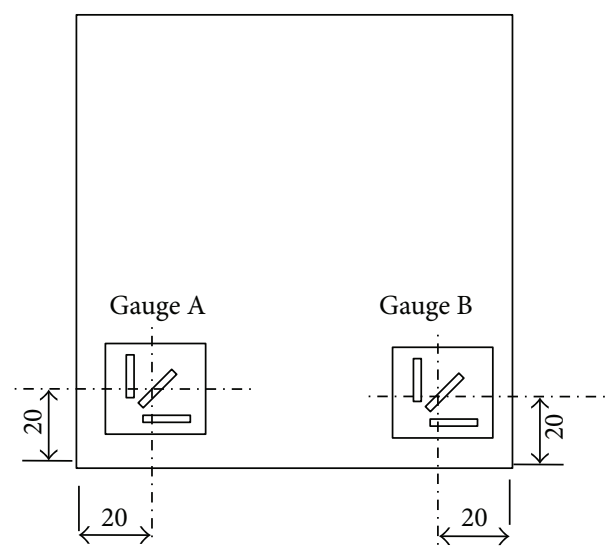

FIgURE 5: Position of three-axis gauges (unit: $\mathrm{mm}$ ).

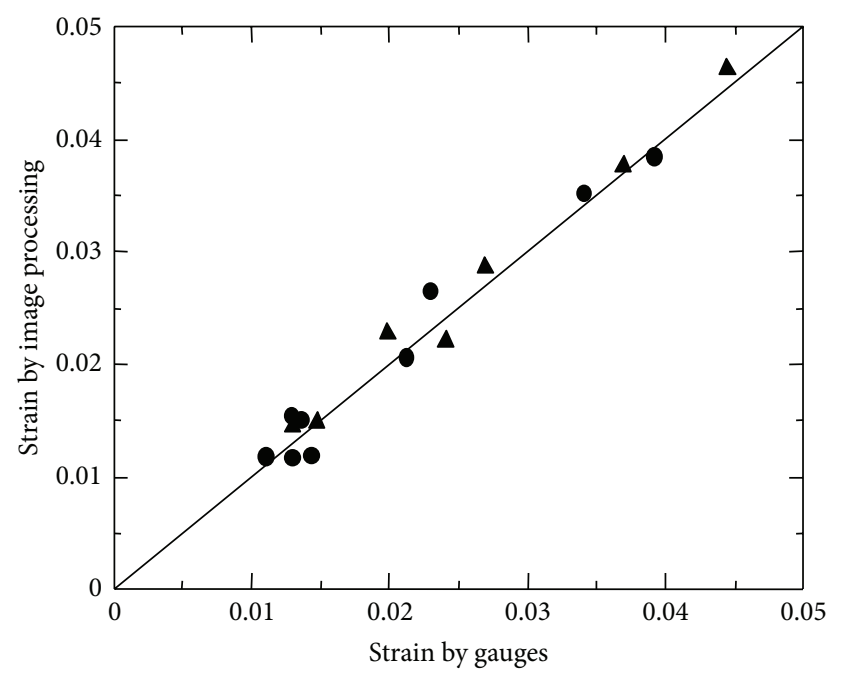

$\Delta$ Gauge A

- Gauge B

FIgURE 6: Comparison with three-axis gauge measurement.

the strain gauges, as shown in Figure 6, especially for a large deformation.

\section{Cycle Loading Tests of Shear Panel Dampers}

3.1. Test Specimens, Test Setup, and Loading History. Before the cyclic loading test, a tensile coupon test was performed to obtain the stress strain curve, as shown in Figure 7 . The yield strength of $80.1 \mathrm{~N} / \mathrm{mm}^{2}$ was defined at the $0.2 \%$ offset of the low-yield steel (LY100), and the elongation reached 60\%, which is about 3 times that of ordinal structural steel SS 400.

The shapes of the shear panel specimens are shown in Figure 8. All test specimens have a uniform plate thickness of $t_{w}=12 \mathrm{~mm}$ (normal width-thickness ratio $W / t_{w}=13$ ). The "reduced width-thickness ratio" $\overline{W / t_{w}}$ defined in (4) [18] is 0.256 . Substituting $\overline{W / t_{w}}=0.256$ into (5), the obtained shear buckling stress $\tau_{\mathrm{cr}}$ is large enough to avoid buckling under cycle loading.

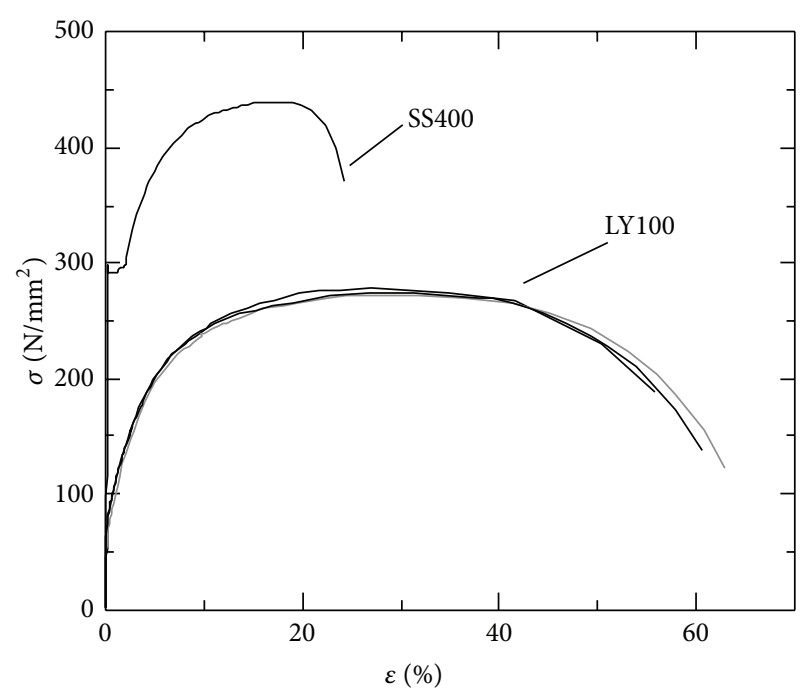

FIGURE 7: Stress-strain relationship in tensile tests.

Consider

$$
\begin{gathered}
\overline{\left(\frac{W}{t_{w}}\right)}=\left(\frac{W}{t_{w}}\right) \sqrt{\frac{\sigma_{y}}{E}}, \\
\frac{\tau_{\mathrm{cr}}}{\tau_{y}}=\frac{1.02}{\left(\overline{W / t_{w}}-0.26\right)}+0.60,
\end{gathered}
$$

where $\sigma_{y}$ is the yield stress, $E$ is the Young's modulus, and $\tau_{\mathrm{cr}}, \tau_{y}$ refer to the yield shear stress and the shear buckling stress, respectively.

The name and characteristics of the four specimens are shown in Table 1. In addition to the square plate (REC), specimens with transition radius (R3, R6.5) and vertical stiffeners along both sides (REC-RIB) were chosen to reinforce the four corners of the square shear panel and then to reduce the stress concentration in the cyclic loading test. All specimens are groove welded to the upper and lower plates $(100 \times 360 \times 16 \mathrm{~mm})$. In order for the upper side to move horizontally, the upper plate is connected to the lower plate through links, as shown in Figure 9. The lower plate is fixed to the base beam with double angles by high-tension bolts. An overall view of the test setup is shown in Figure 10. A cyclic lateral load was applied at the tip of the upper beam through a $W$-type leveling apparatus (gravity simulator) that keeps the distance between the upper loading beam and base constant. As shown in Figure 11, the increment of the shear displacement for all specimens in each loading cycle is $\pm 1 \delta_{y}$, where $\delta_{y}=5 \mathrm{~mm}$ is the shear yield displacement of the specimen REC corresponding to the $0.2 \%$ offset yield stress of the material. The displacement history is imposed on the specimens through 5 9 cycles up to the displacement where failure occurs.

3.2. Strain Distribution Measurement System. The strain measurement system consists of two digital cameras, the image processing program and experimental equipment. The basic features of the digital cameras are shown in Table 2. 


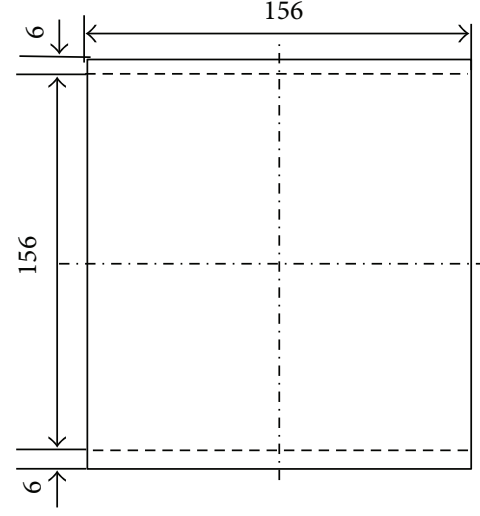

(a) REC

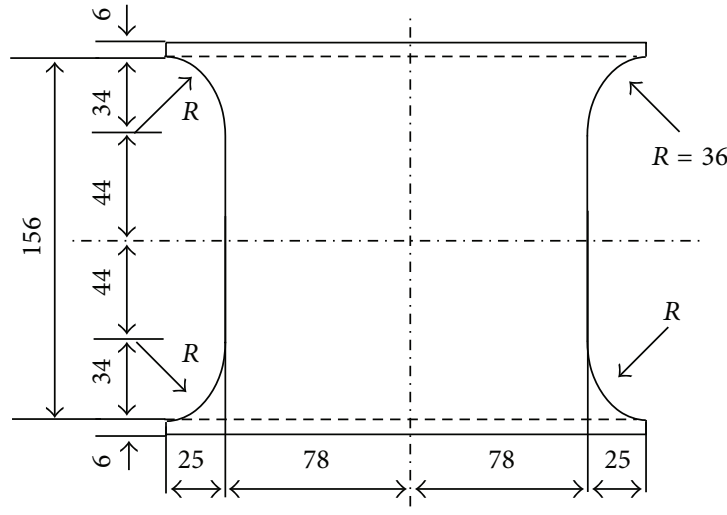

(b) R3

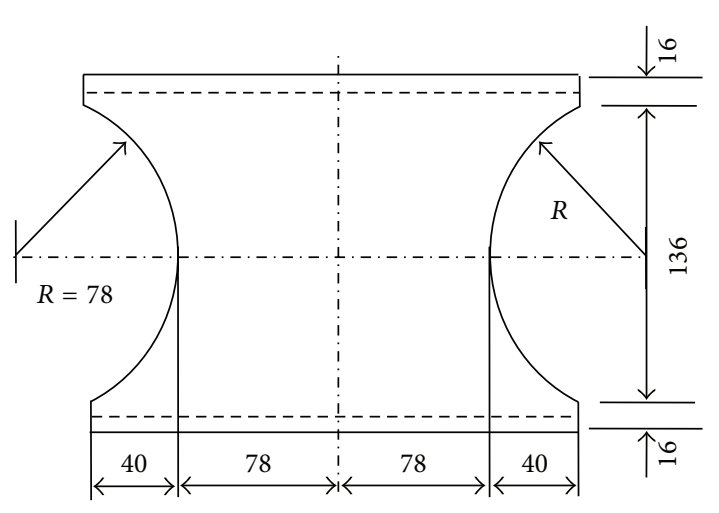

(c) R6.5

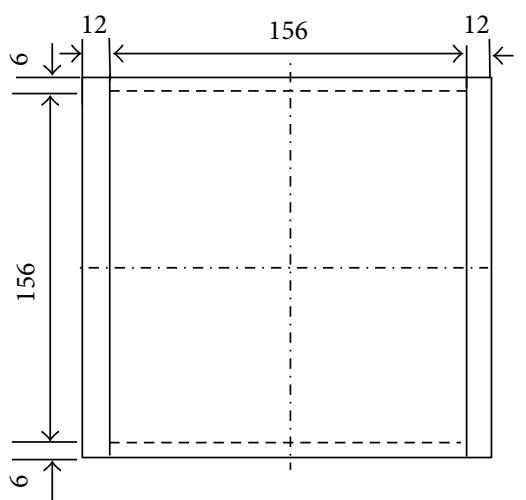

(d) REC-RIB

Figure 8: Specimen dimensions (mm).

TABLE 1: Test specimens.

\begin{tabular}{|c|c|}
\hline Specimen & Characteristics \\
\hline (a) REC & $156 \times 156 \mathrm{~mm}$ square plate \\
\hline (b) R3 & With a transition radius $R=3 t_{w}$ at the four corners \\
\hline (c) R6.5 & With a transition radius $R=6.5 t_{w}$ at both sides \\
\hline (d) REC-RIB & With vertical stiffeners along the both sides \\
\hline
\end{tabular}

TABLE 2: Basic features of the utilized camera.

\begin{tabular}{lc}
\hline Image recorder & Nikon digital camera D40X \\
\hline Lens type & AF-S DX ZOOM Nikkor ED 18 55 mm, \\
Filter size & F 3.5 5.6 G \\
Pixel & $52 \mathrm{~mm}$ \\
& $3872 \times 2592(10 \mathrm{M})$
\end{tabular}

The position of the cameras relative to the specimen is shown in Figures 12(a) and 12(b). One half of the specimen (bottom of the web) was set to be the strain measurement domain and the optical axes of the cameras were vertical to the specimen.

3.3. Results and Discussion. The hysteretic relationship of the normalized shear load $\left(Q / Q_{y}\right)$ to shear deformation $(\gamma=$ $\delta / H)$ for cyclically tested specimens is shown in Figure 13, where $Q_{y}=86.5 \mathrm{kN}$ is the yield shear force corresponding to the yield displacement, and $H=156 \mathrm{~mm}$ is the height of the specimen. The amount of shear deformation of one cycle is equivalent to a shear strain of 3.2\%. Figure 14 shows the deformation and destruction appearance of each type of specimen in the cyclic loading test. The strain distribution in the test specimens during the 3rd cycle is shown in Figure 15, where the vertical axis expresses the accumulated von Mises equivalent strain $\bar{\varepsilon}$ [19] calculated using (6) and (7) as follows:

$$
\begin{gathered}
d \bar{\varepsilon}=\sqrt{\frac{4}{3}\left(\left(d \varepsilon_{x}^{p}\right)^{2}+\left(d \varepsilon_{y}^{p}\right)^{2}+d \varepsilon_{x}^{p} d \varepsilon_{y}^{p}+\frac{1}{4}\left(d \gamma_{x y}^{p}\right)^{2}\right)}, \\
\bar{\varepsilon}=\int_{0}^{t} d \bar{\varepsilon},
\end{gathered}
$$

where $d \varepsilon_{x}^{p}, d \varepsilon_{y}^{p}$, and $d \gamma_{x y}^{p}$ are the strain increments in the $x$ and $y$ directions and shear strain, respectively, and the horizontal axis denotes the positions of the marks on the panel. Considering the symmetry of geometry, boundary constraint and loading, the accumulated von Mises equivalent strain in whole region is symmetrical, and the values of $1 / 4$ part of the specimens are shown in Figures 15(a) 15(d).

The maximum load and maximum shear deformation of each specimen are shown in Table 3. From Figures 13 to 15, the following are considered. 


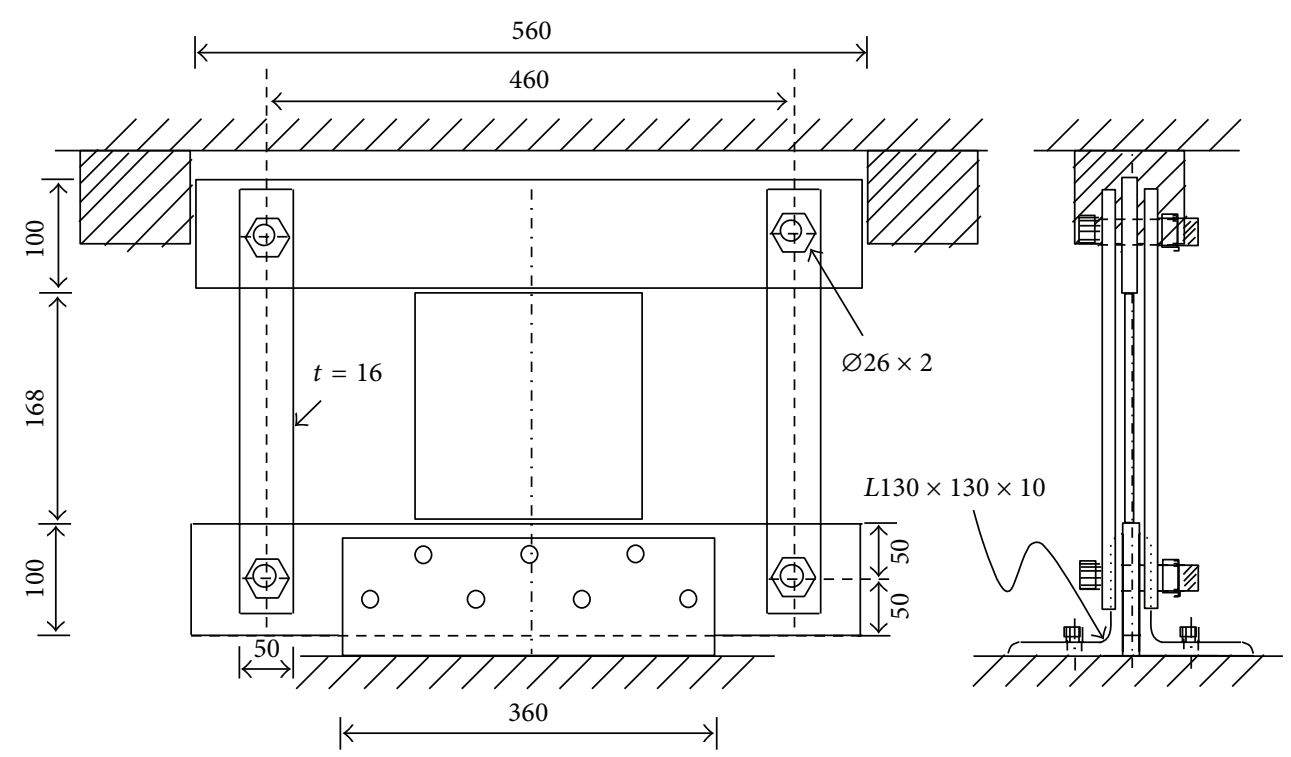

FIGURE 9: Fixture and boundary condition of the specimen (Unit: mm).

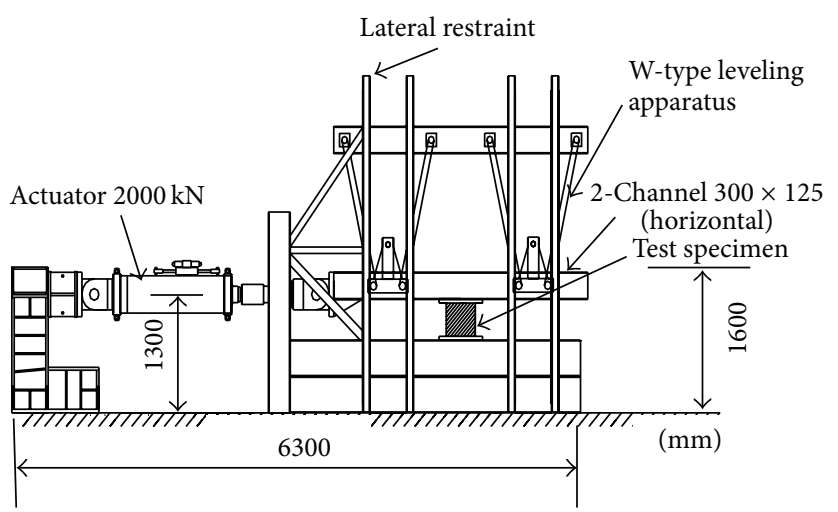

FIGURE 10: Experimental equipment for the cyclic loading test.

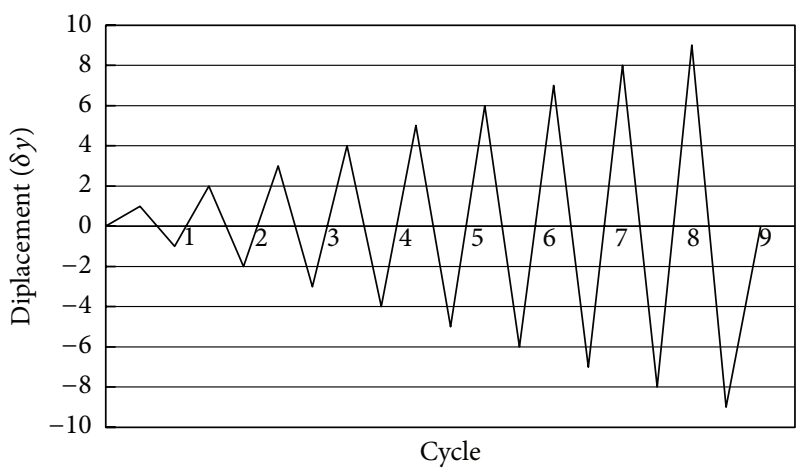

FIGURE 11: Loading history.

(1) Square Web Plate (REC). Figure 13(a) shows the hysteretic curve of shear force versus shear deformation of REC. A shear load $Q_{\max }=2.2 Q_{y}$ and a shear deformation of $\gamma_{\max }=16 \%$ ( i.e., $\delta=5 \delta_{y}$ ) are obtained, which is the lowest among the four specimens. Fracturing was observed at the diagonal
TAble 3: Maximum load and maximum shear deformation.

\begin{tabular}{lcc}
\hline Specimen & $Q_{\max } / Q_{y}$ & $\gamma_{\max }(\%)$ \\
\hline (a) REC & 2.20 & 16.0 \\
(b) R3 & 2.25 & 23.0 \\
(c) R6.5 & 3.30 & 28.5 \\
(d) REC-RIB & 3.35 & 25.0 \\
\hline
\end{tabular}

corners during the 4th cycle of loading as shown in Figure 14(a) and then it progressed along with increasing horizontal loading. Finally, it resulted in destruction. The strain distribution of REC is shown in Figure 15(a). The equivalent strain in the panel corner calculated using (7) is 0.17 , which is about 5 times the value in the center part. It is clear that remarkable strain concentration is observed at the panel corners compared with other specimens.

(2) R3. The hysteretic curve of specimen R3, which is a shear panel with a transition radius of $R=3 t_{w}=36 \mathrm{~mm}$ at the four corners, is shown in Figure 13(b). From the curve, 


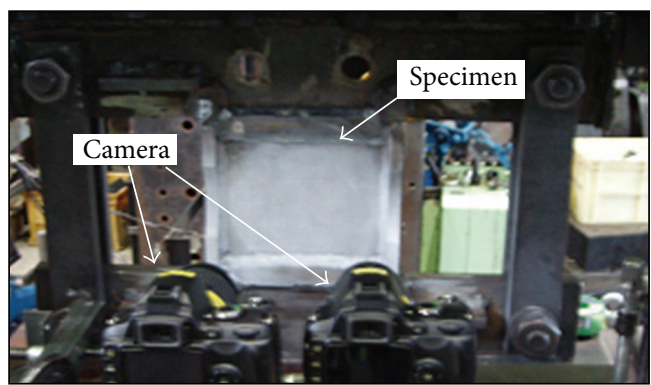

(a)

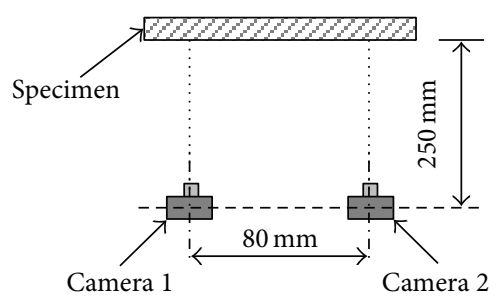

(b)

FIGURE 12: Camera setup.

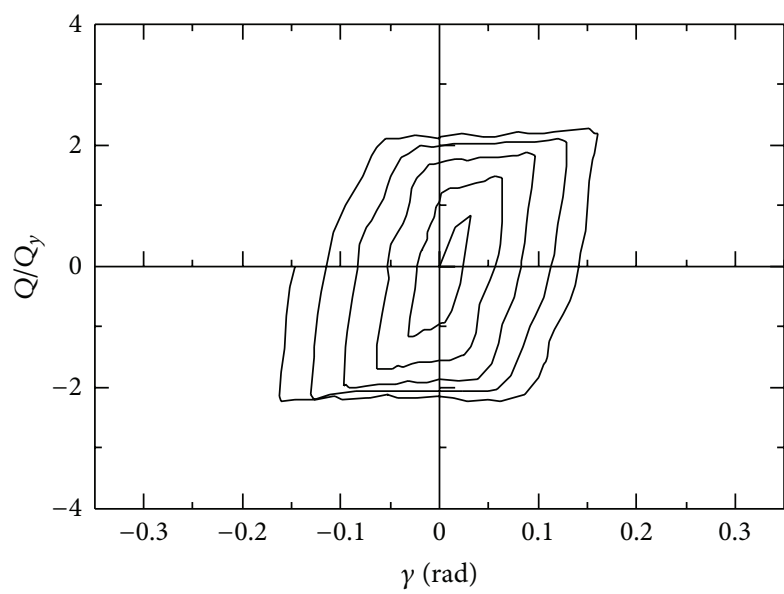

(a) REC

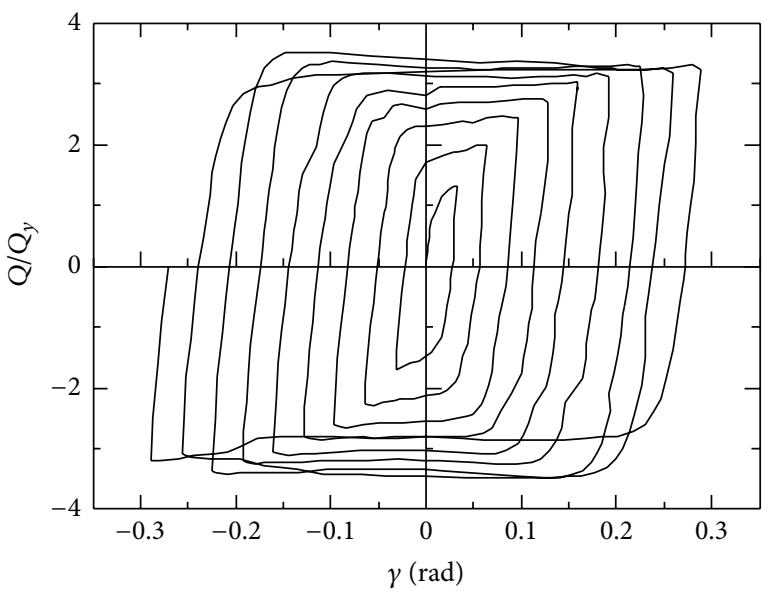

(c) R6.5

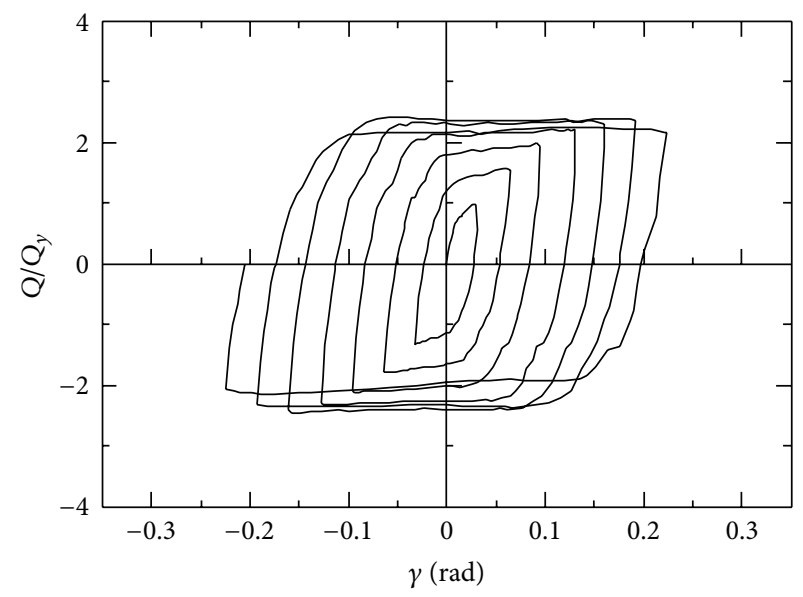

(b) R3

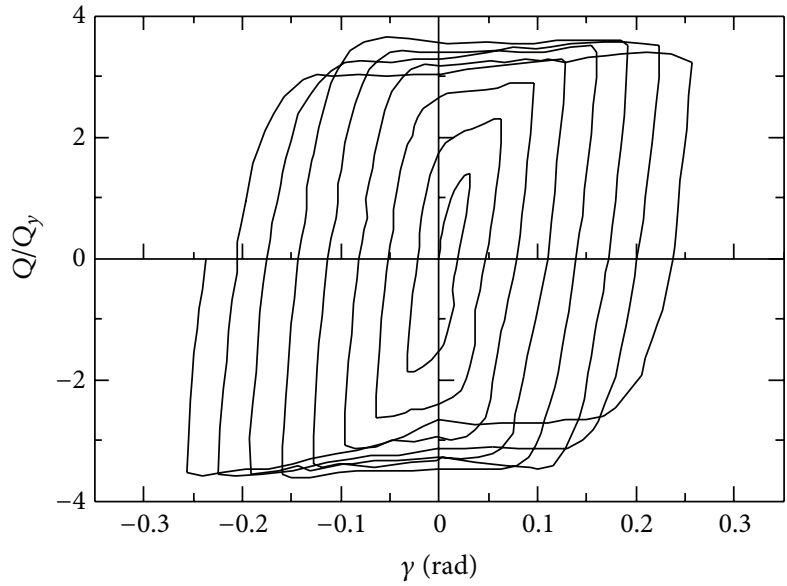

(d) REC-RIB

FIGURE 13: Hysteretic shear load-displacement curves.

the shear deformation max is $23 \%\left(\delta=7 \delta_{y}\right)$, which is $44 \%$ greater than that of REC, whereas the maximum shear load $Q_{\max }=2.25 Q_{y}$ is almost the same as REC. The strain distribution of R3 is shown in Figure 14(b). Compared with Figure 15(a), the location of the maximum strain moved from the panel corners to the middle part of the arc. The maximum value reduced to 0.085 , which is about half of that of REC. Moreover, the strain in the region near the center of the panel is larger than that of REC. It is said that the strain concentration at the four corners is reduced by the radius at the corners. The reduction in stress concentration significantly contributes to improving the cyclic performance of shear devices because it delays the initiation of fractures at the panel corners. The final destruction is shown in Figure 14(b). 


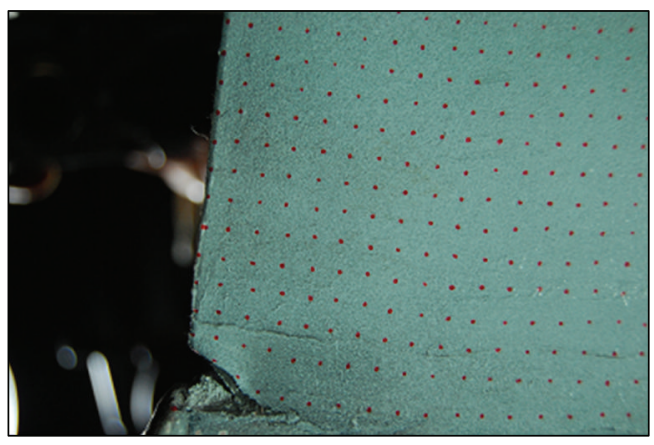

(a) REC

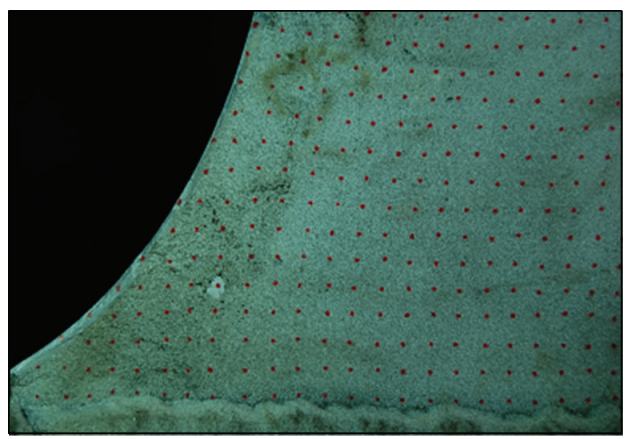

(c) R6.5

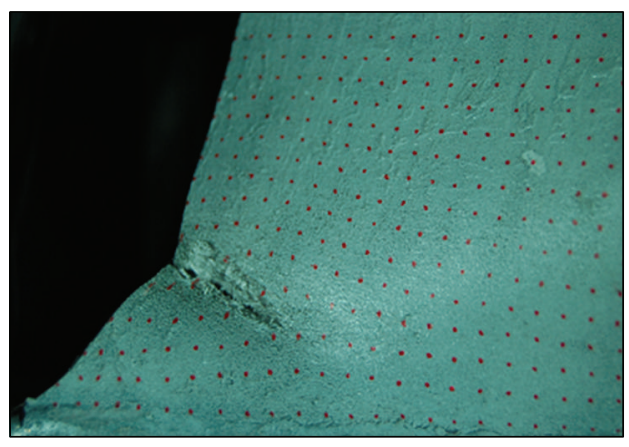

(b) R3

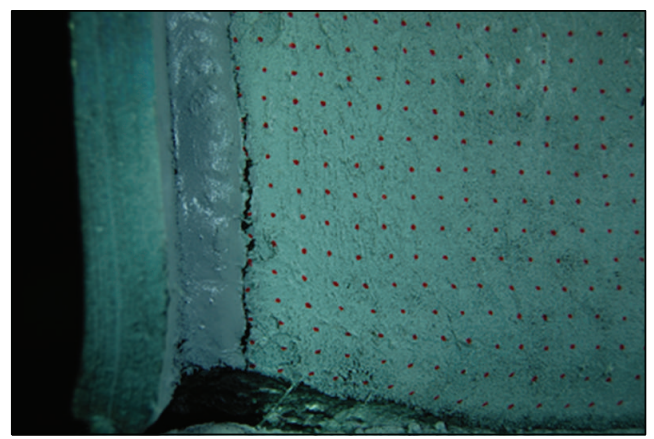

(d) REC-RIB

FIGURE 14: Deformation and destruction appearance of the test specimens.

(3) R6.5. The hysteretic curve of specimen R6.5 with a transition radius of $R=6.5 t_{w}=78 \mathrm{~mm}$ at both sides is shown in Figure 13(c). The maximum shear deformation is $28.5 \%$ $\left(\delta=9 \delta_{y}\right)$, which is the largest among the four specimens and about $24 \%$ larger than R3. Following the increase in ductility, the maximum shear load $Q_{\max }$ rises up to $3.3 Q_{y}$, which is about $44 \%$ higher than R3. Figure 15(c) shows the strain distribution in R6.5. Similar to Figure 14(b), large strain values appear in the region along the arc of the shear panel. However, the maximum strain is reduced to 0.073 compared with R3, which is about $15 \%$ less than R3. The strain in the region near the center of the panel is larger than R3. This result implies that the relaxation of the strain concentration in the four corners leads to an increase in ductility and improves the energy absorption capacity of the shear panel.

(4) REC-RIB. Figure 13(d) shows the hysteretic curve of specimen REC-RIB with vertical stiffeners along both edges. Compared with R6.5, the maximum shear load $Q_{\max }=3.35 Q_{y}$ is almost the same but the shear deformation decreases to $25 \%$, because of the early crack initiation at the end of stiffeners, as shown in Figure 14(d). The small and uniform strain distribution in specimen REC-RIB is shown in Figure 15(d), where it is observed in the entire shear panel and ranges between 0.035 and 0.045 .

\section{Improved Shear Panel Dampers}

As the REC-RIB was mentioned in Section 3.2, the initiation of cracks at the ends of the stiffeners occurred in an early
TABLE 4: Improved shear panel dampers.

\begin{tabular}{lc}
\hline Specimen & Characteristics \\
\hline $\begin{array}{l}\text { REC-RIB-RF } \\
\text { REC-RIB- }\end{array}$ & $\begin{array}{c}\text { REC-RIB with reinforcing plates at the upper } \\
\text { and bottom edges of shear panel } \\
\text { RF-R }\end{array}$ \\
\hline
\end{tabular}

stage, which leads to a lower shear deformation comparing with R6.5. On the other hand, the effect of stiffeners on the right and left sides of the panel produces uniform and small strain distribution in the panel. It suggests that if the ends of the stiffeners are reinforced well to prevent crack initiation, higher seismic performance and larger deformation capacity can be expected. Therefore, two improved shear panel damper (REC-RIB-RF and REC-RIB-RF-R), as shown in Table 4 and Figure 16, were studied. In REC-RIB$\mathrm{RF}$, reinforcing plates were added at the upper and bottom edges of the shear panel to reinforce the weld zones, and curved vertical flanges were added along both sides instead of the rectangle stiffeners in REC-RIB-RF-R.

Figures 17(a) and 17(b) show the hysteretic curves of shear force versus shear deformation obtained from the cyclic loading tests of REC-RIB-RF and REC-RIB-RF-R, respectively. In order to compare the improved SPDs with other four types, the envelope curves of all types of SPDs were obtained from the hysteretic curves as shown in Figure 18, and the total energy dissipation which sums up the dissipation in each cycle is shown Figure 19. 


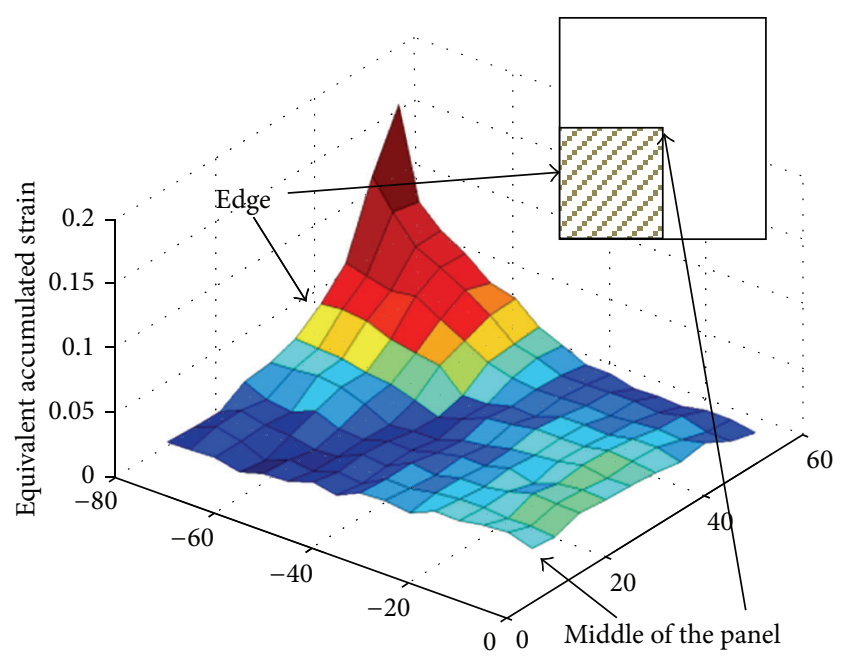

Positions of the marks

(a) REC

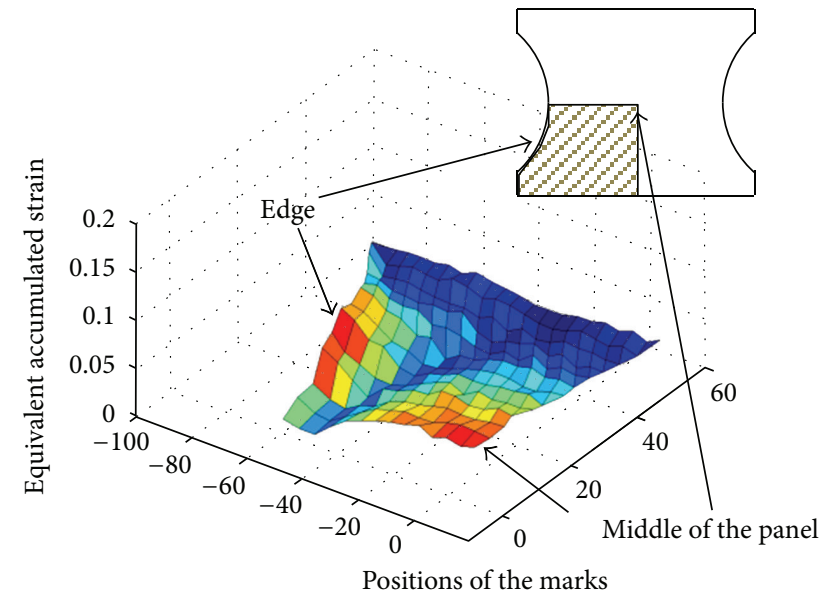

(c) R6.5

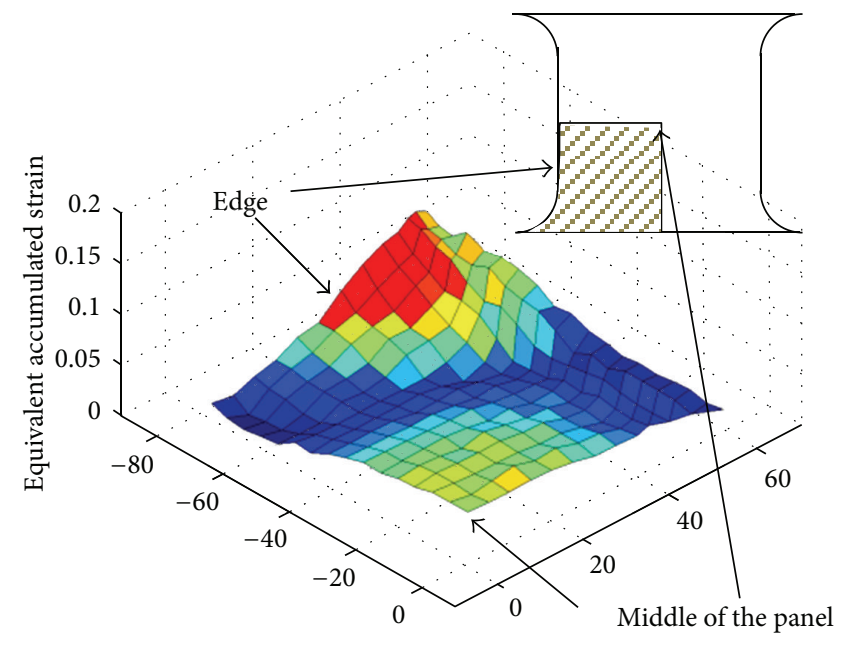

Positions of the marks

(b) R3

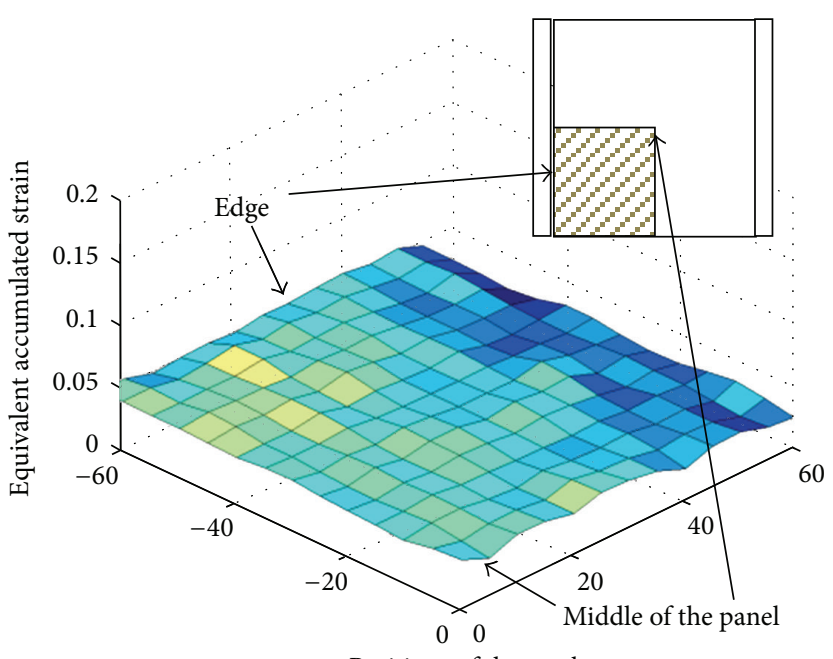

Positions of the marks

(d) REC-RIB

FIGURE 15: Strain distributions obtained using image processing.

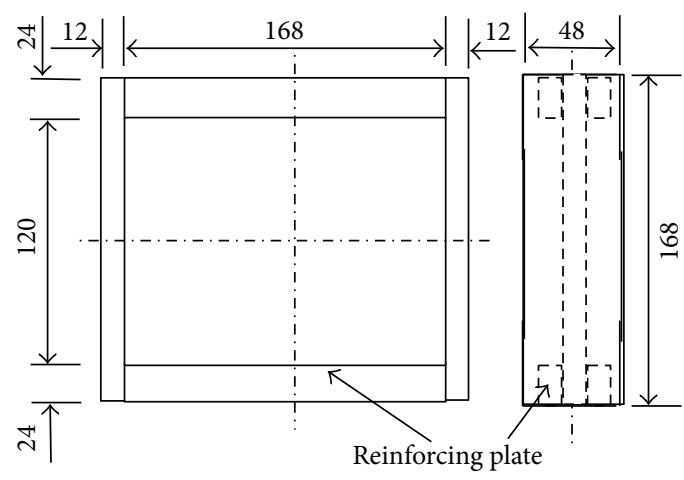

(a) REC-RIB-RF

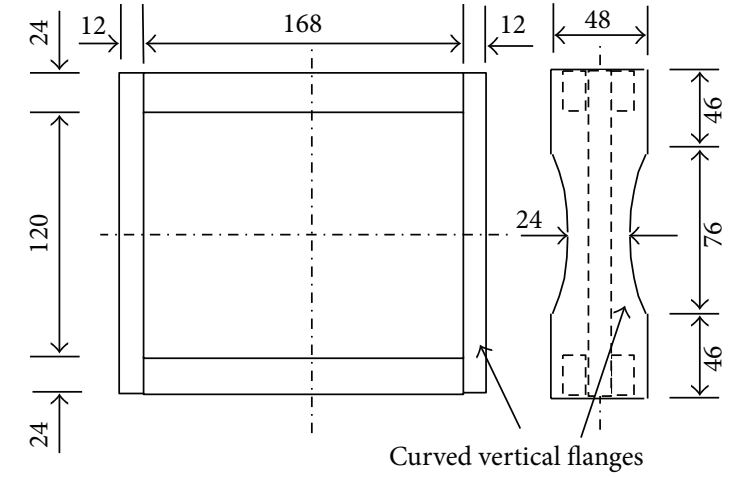

(b) REC-RIB-RF-R

FIGURE 16: Shapes of the improved shear panel dampers (Unit: mm). 


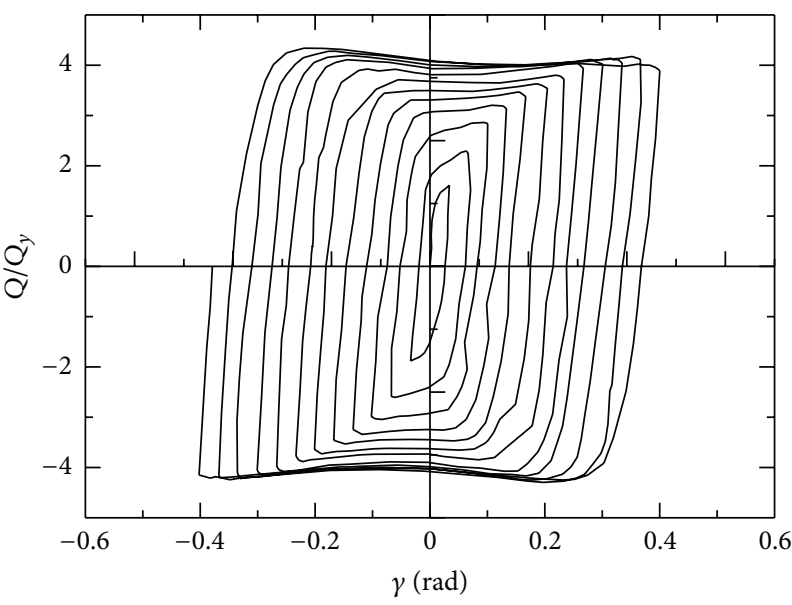

(a) REC-RIB-RF

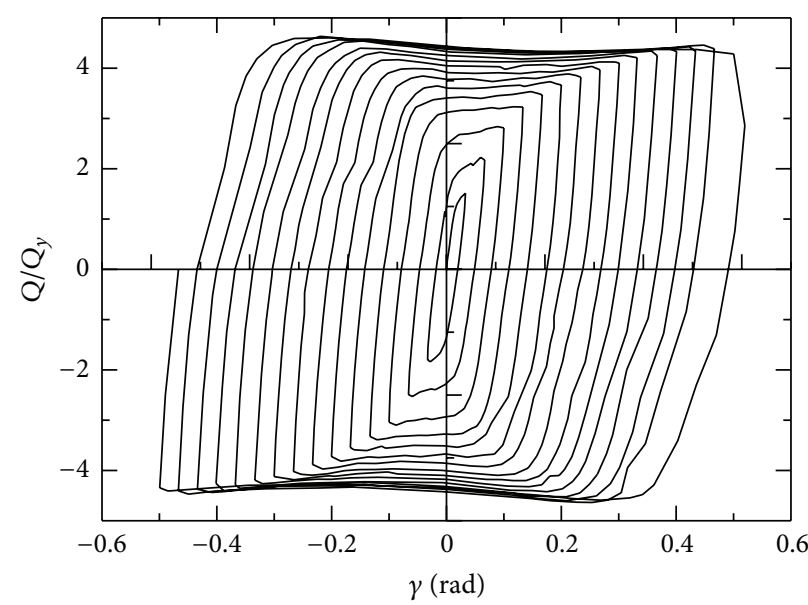

(b) REC-RIB-RF-R

FIGURE 17: Hysteresis curves of the improved shear panel dampers.

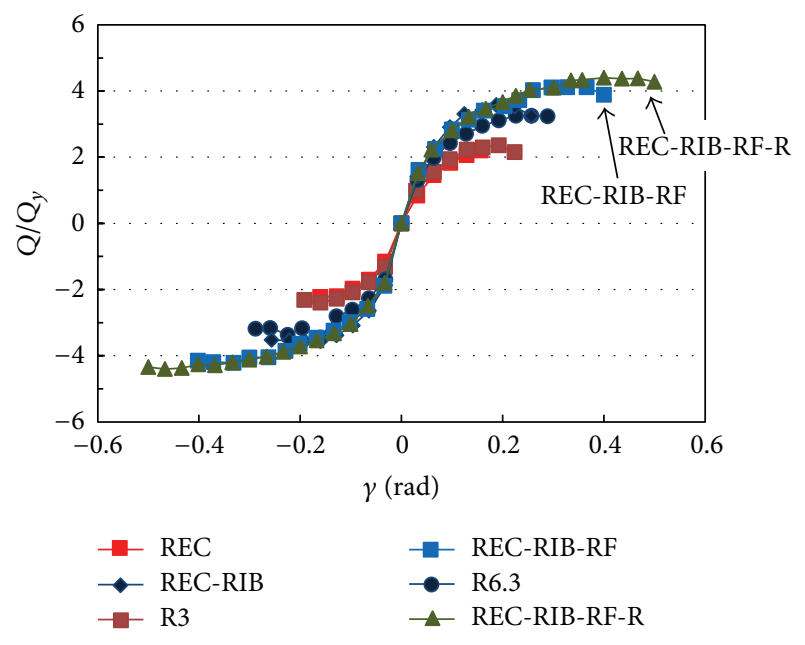

FIGURE 18: Envelopesof the hysteresis curves.

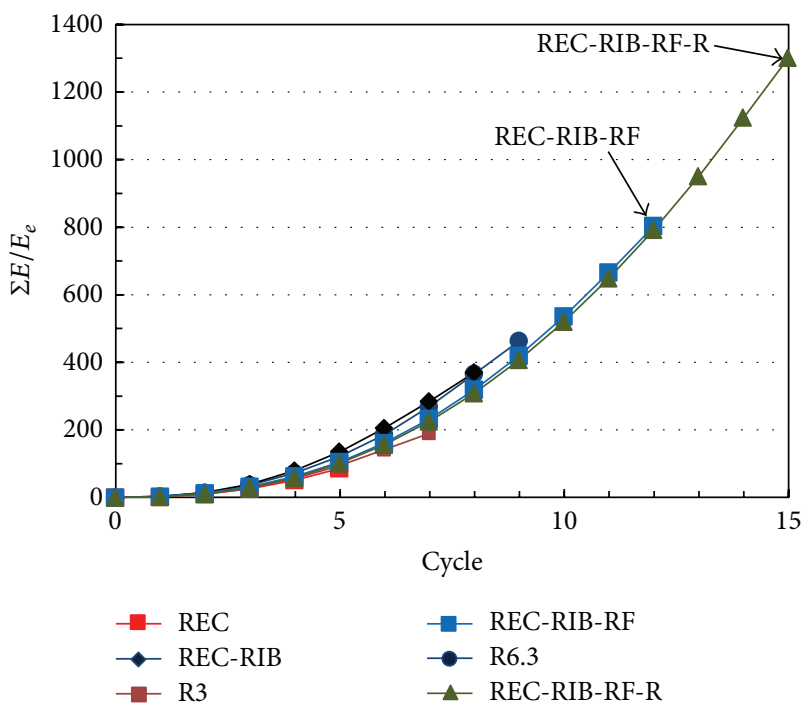

FIGURE 19: Comparison of accumulated absorbing energy.
Comparing with the REC-RIB (Figure 13(d)), the shear deformation of REC-RIB-RF is improved to $\gamma_{\max }=40 \%$, which is $60 \%$ greater than REC and about $40 \%$ higher than R6.5. It is clear that the crack process of fracture could be delayed by the reinforcement of the welding portion at the ends of the stiffeners, and highly improved the energy absorption performance of the SPD. Moreover, by using the curved vertical flanges in REC-RIB-RF-R, the maximum shear deformation drastically increased to $50 \%$, which is the largest among all types of specimens and 20\% larger than REC-RIB-RF. It is considered that the stress concentration at the ends of the stiffeners was transferred to the central part due to the stiffener width reduction at the middle part. The reduction of the stress concentration effectively delayed the initiation of fractures and contributed to substantially improve the deformation capacity of the SPD.

\section{Summary and Conclusions}

To develop the low-yield steel shear panel damper with high deformation capacity for bridge structure, the strain distribution properties of the shear panel damper under cyclic loading were investigated by the digital image processing technology. With the presented large strain distribution measurement system, strain distributions of four types of shear panel dampers were obtained along with the hysteretic load-displacement curves. The relationship between the shear deformation performance and the stress distribution in the panels was studied to identify the crack initiation mechanism in the shear panel dampers. Based on the investigation, the shear panel damper was improved to achieve a high deformation capacity, which contributes to make it possible to be a bridge horizontal bearing.

\section{References}

[1] M. Nakashima, S. Iwai, M. Iwata et al., "Energy dissipation behaviour of shear panels made of low yield steel," Earthquake 
Engineering and Structural Dynamics, vol. 23, no. 12, pp. 12991313, 1994.

[2] I.-R. Choi and H.-G. Park, "Hysteresis model of thin infill plate for cyclic nonlinear analysis of steel plate shear walls," Journal of Structural Engineering, vol. 136, no. 11, pp. 1423-1434, 2010.

[3] M. Raquibul Hossain, M. Ashraf, and F. Albermani, "Numerical modelling of yielding shear panel device for passive energy dissipation," Thin-Walled Structures, vol. 49, no. 8, pp. 10321044, 2011.

[4] C. C. McDaniel, C.-M. Uang, and F. Seible, "Cyclic testing of built-up steel shear links for the new bay bridge," Journal of Structural Engineering, vol. 129, no. 6, pp. 801-809, 2003.

[5] T. Moriuchi and T. Takeuchi, "Examples of function-separated bearing system," Journal of Bridge and Foundation, vol. 37, no. 7, pp. 25-30, 2003.

[6] T. Aoki, Y. Liu, T. Takaku, and Y. Fukumoto, "A new type of shear panel dampers for highway bridge bearings," in Proceedings of the 5th European Conference on Steel and Composite Structures, Graz, Austria, 2008.

[7] Y. Liu, T. Aoki, T. Takaku, and Y. Fukumoto, "Cyclic loading tests of shear panel damper made of low yield steel," Journal of Structural Engineering A, vol. 53, pp. 560-567, 2007.

[8] T. Aoki, Y. Liu, T. Takaku, M. Uenoya, and Y. Fukumoto, "Experimental investigation of tapered shear-type seismic devices for bridge bearings," in Proceedings of the 8th Pacific Structural Steel Conference (PSSC '07), Steel Structures in Natural Hazards, pp. 111-117, Wairakei, New Zealand, March 2007.

[9] Z. Tan, L. Melin, and C. Magnusson, "Application of an image processing technique in strain measurement in sheet metal forming," Journal of Materials Processing Tech, vol. 33, no. 3, pp. 299-310, 1992.

[10] H. Deng, J. B. Wiskel, A. Ben-Zvi, M. D. Rieder, and H. Henein, "Strain measurement of forming process using digital imaging," Materials Science and Technology, vol. 25, no. 4, pp. 527-532, 2009.

[11] W. N. Sharpe Jr., J. Pulskamp, D. S. Gianola, C. Eberl, R. G. Polcawich, and R. J. Thompson, "Strain measurements of silicon dioxide microspecimens by digital imaging processing," Experimental Mechanics, vol. 47, no. 5, pp. 649-658, 2007.

[12] B. Fischer, S. Vorberg, R. Völkl, M. Beschliesser, and A. Hoffmann, "Creep and tensile tests on refractory metals at extremely high temperatures," International Journal of Refractory Metals and Hard Materials, vol. 24, no. 4, pp. 292-297, 2006.

[13] M. Tsuji and T. Meshii, "Extending image processing strain measurement system to evaluate fracture behavior of wallthinned pipes," Nuclear Engineering and Design, vol. 241, no. 9, pp. 3605-3612, 2011.

[14] M. Sakai and S. Matsuura, "Strain-controlled low cycle fatigue test system with image-based measurement," Abiko Research Laboratory Report U00068, 2001.

[15] R. C. Gonzalez and R. E. Woods, Digital Image Processing, Addison-Wesley, Reading, Mass, USA, 1992.

[16] T. Acharya and A. K. Ray, Image Processing-Principles and Applications, Wiley Inter Science, 2006.

[17] T. B. Jacob Fish, A First Course in Finite Elements, John Wiley \& Sons, 2007.

[18] Y. Takahashi and Y. Shinabe, "Experimental study on restoring force characteristics of shear yielding thin steel plate elements," Journal of Structural and Construction Engineering, vol. 494, pp. 107-114, 1997.

[19] Y. C. Fung, Foundations of Solid Mechanics, Prentice-Hall, 1965. 

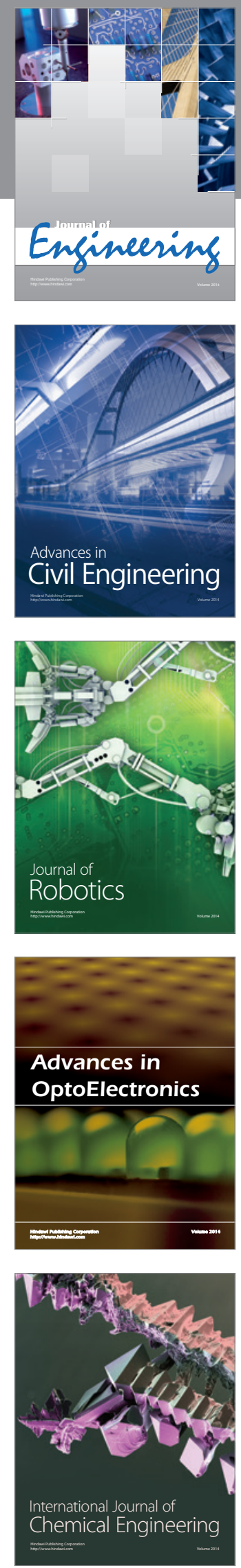

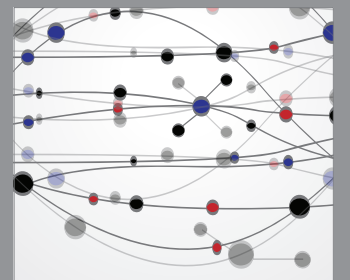

The Scientific World Journal
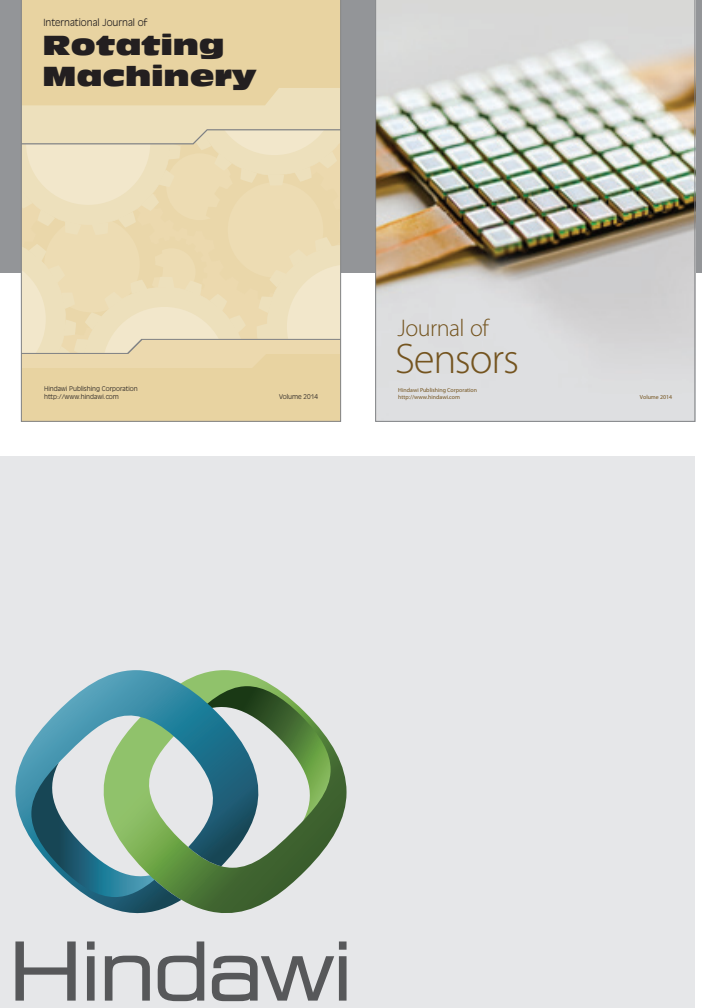

Submit your manuscripts at http://www.hindawi.com
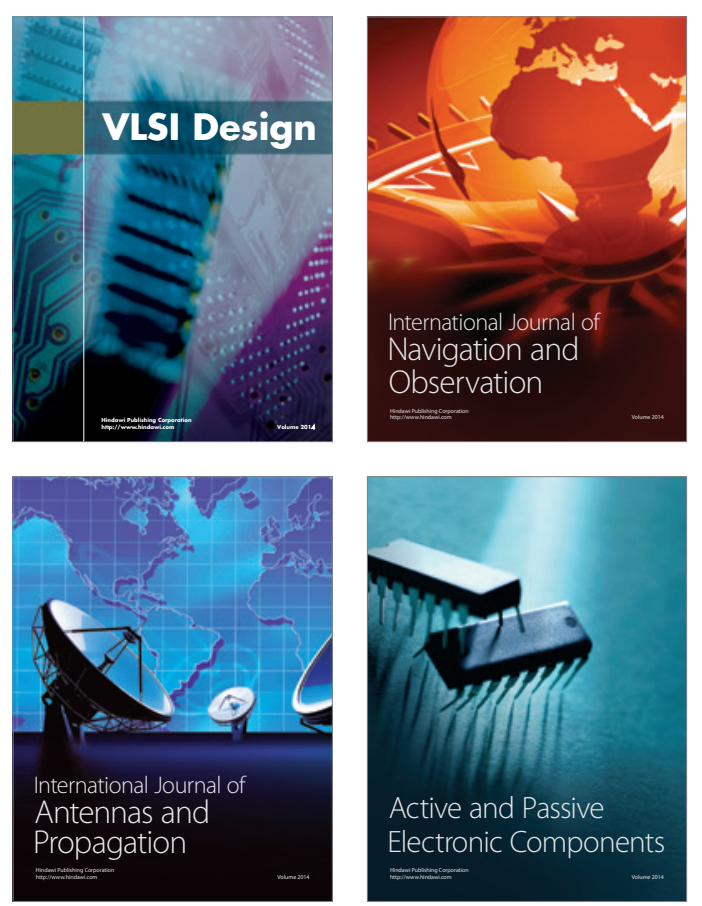
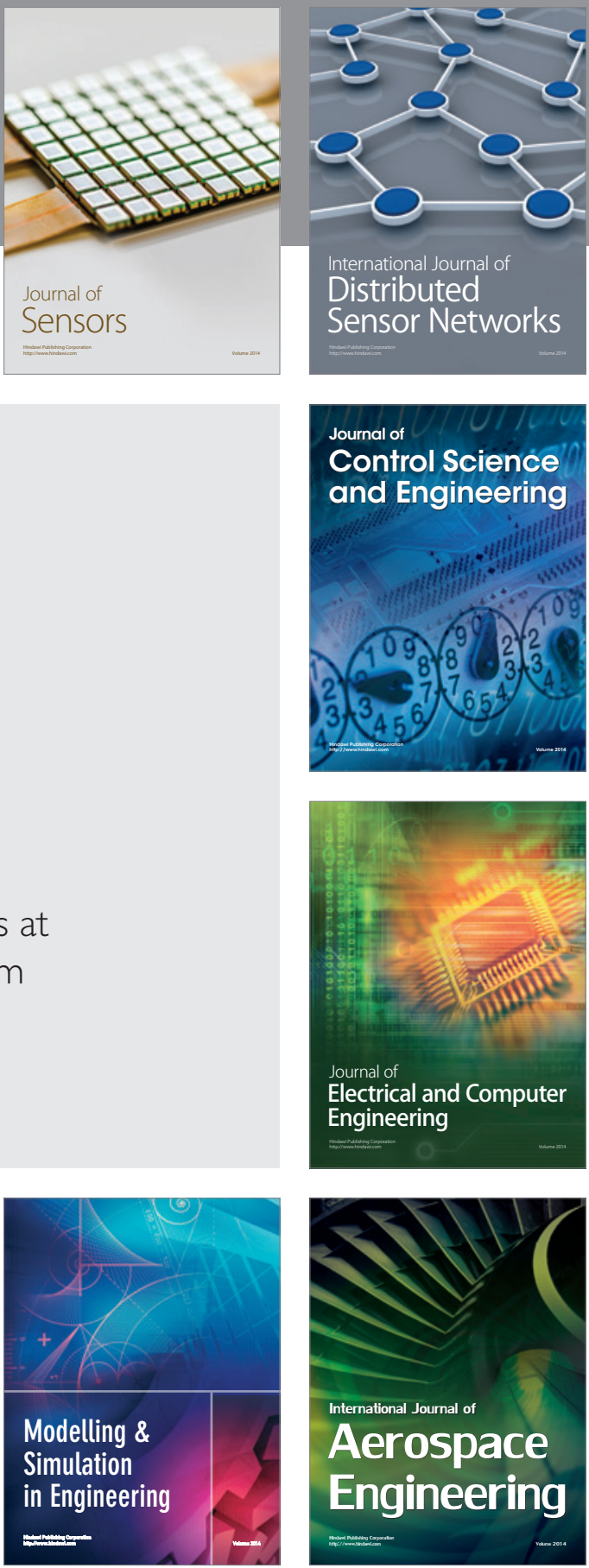

Journal of

Control Science

and Engineering
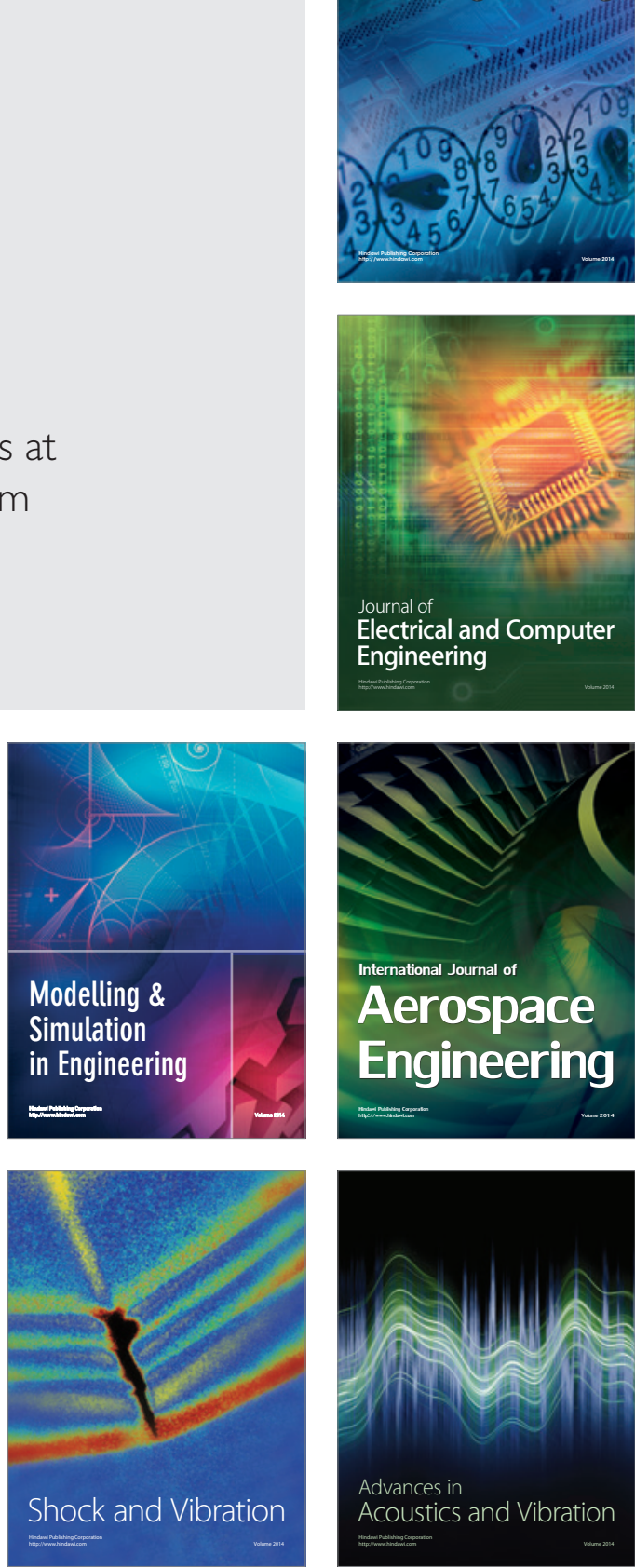